\title{
The Toxicology of Bath Salts: A Review of Synthetic Cathinones
}

\author{
Jane M. Prosser • Lewis S. Nelson
}

Published online: 23 November 2011

(C) American College of Medical Toxicology 2011

\begin{abstract}
Synthetic cathinones have recently emerged and grown to be popular drugs of abuse. Their dramatic increase has resulted in part from sensationalized media attention as well as widespread availability on the Internet. They are often considered "legal highs" and sold as "bath salts" or "plant food" and labeled "not for human consumption" to circumvent drug abuse legislation. Cathinone is a naturally occurring beta-ketone amphetamine analogue found in the leaves of the Catha edulis plant. Synthetic cathinones are derivatives of this compound. Those that are being used as drugs of abuse include butylone, dimethylcathinone, ethcathinone, ethylone, 3- and 4-fluoromethcathinone, mephedrone, methedrone, methylenedioxypyrovalerone (MDPV), methylone, and pyrovalerone. Synthetic cathinones are phenylalkylamines derivatives, and are often termed "bk-amphetamines" for the beta-ketone moiety. They may possess both amphetaminelike properties and the ability to modulate serotonin, causing distinct psychoactive effects. Desired effects reported by users of synthetic cathinones include increased energy, empathy, openness, and increased libido. Cardiac, psychiatric, and neurological signs and symptoms are the most common adverse effects reported in synthetic cathinone users who require medical care. Deaths associated with use of these compounds have been reported. Exposure to and use of synthetic cathinones are becoming increasingly popular despite a lack of scientific research and understanding of
\end{abstract}

\footnotetext{
J. M. Prosser $(\bowtie)$

Weill Cornell Medical Center,

New York, NY, USA

e-mail: jprosser100@gmail.com

\section{S. Nelson}

New York University School of Medicine,

New York City Poison Control Center,

New York, NY, USA
}

the potential harms of these substances. The clinical similarities to amphetamines and MDMA specifically are predictable based on the chemical structure of this class of agents. More work is necessary to understand the mechanisms of action, toxicokinetics, toxicodynamics, metabolism, clinical and psychological effects as well as the potential for addiction and withdrawal of these agents.

Keywords Cathinone $\cdot$ Mephedrone $\cdot$ Methedrone $\cdot$ MDPV . Methylone $\cdot$ Bath salts

\section{Background}

Synthetic cathinones have recently emerged and grown to be popular drugs of abuse. Their dramatic increase has resulted in part from sensationalized media attention as well as widespread availability. They are often considered "legal highs" and sold as "bath salts" or "plant food" and labeled "not for human consumption" to circumvent drug abuse legislation. They can be obtained through "head shops," Internet websites, and local drug suppliers.

The legal status is variable by jurisdiction and rapidly changing, however they were initially legal in the UK and Europe. "Legal high" is a term often used to refer to drugs that are considered by users to fall outside of drug regulatory laws They are generally labeled "not for human consumption" to subvert regulatory control. Prior to 2009, the UK Poisons Information Service had no telephone inquiries related to synthetic cathinones. However over a 1year period from 2009 to 2010, the number of inquiries regarding synthetic cathinone derivatives equaled the number of calls about cocaine and MDMA [1]. Google Insights, a web application that tracks search terms, shows almost no searches for mephedrone before 2008. There has 
since been a remarkable rise in the number of searches, peaking in 2009, with the highest number of searches originating from the UK [2]. For a comprehensive review of existing data, Pubmed, Medline, Google, Google Scholar were searched using the following terms: bath salts, butylone, club drugs, dimethylcathinone, ethcathinone, ethylone, 3- and 4-fluoromethcathinone, mephedrone, methedrone, methylenedioxypyrovalerone (MDPV), methylone, plant food and pyrovalerone.

Cathinone ((S)-2-amino-1-phenyl-1-propanone) is a naturally occurring beta-ketone amphetamine analogue found in the leaves of the Catha edulis (Khat) plant. Chewing the leaves of this plant for stimulant effects is popular in certain Middle Eastern countries, particularly Yemen [3]. Cathinone is found in the leaves of the plants only when fresh, and for this reason leaves can be chewed for only a few days after harvesting. Cathinone causes amphetamine-like sympathomimetic effects, including tachycardia and hypertension as well as psychoactive effects euphoria and increased alertness. Khat chewing has been linked to increased risk of myocardial infarction, dilated cardiomyopathy, and duodenal ulcers [3].

Synthesis of cathinone derivatives has been reported since the late 1920s. Methcathinone was synthesized in 1928 and mephedrone in 1929 [4, 5]. A few of these derivatives have been investigated for medical use. Currently, bupropion is the only cathinone derivative that carries a medical indication in the US and Europe. It is a ring-substituted cathinone, prescribed for the treatment of depression and for use as a smoking-cessation aid [6]. Others have been investigated, but were ultimately unsuccessful due to severe side effect profiles. Methcathinone was used in Russia as an antidepressant in the 1930s and 1940s. Also known as "Cat" and "Jeff," it has been used recreationally most often in countries formerly part of the Soviet Union, but also gained popularity in the United States, particularly in Michigan, in the 1990s [7]. Another derivative, pyrovalerone was investigated for use as a prescription drug to treat chronic fatigue, lethargy, and obesity but was withdrawn due to abuse and dependency in users [8-10].

Numerous synthetic cathinone derivatives have become popular for use as "legal highs." Exactly when these derivatives gained popularity amongst club goers and others seeking new drugs of abuse is difficult to pinpoint, but mentions in Internet drug forums began in 2007 [11]. Synthetic cathinones that have been found in these products include butylone, dimethylcathinone, ethcathinone, ethylone, 3 and 4-fluoromethcathinone, mephedrone, methedrone, MDPV, methylone, and pyrovalerone (see Table 1 $[6,12-14])$.

Interest in synthetic cathinones as drugs of abuse developed in part due to decreased availability and purity of the
Table 1 Synthetic cathinones used as drugs of abuse with chemical names and structures

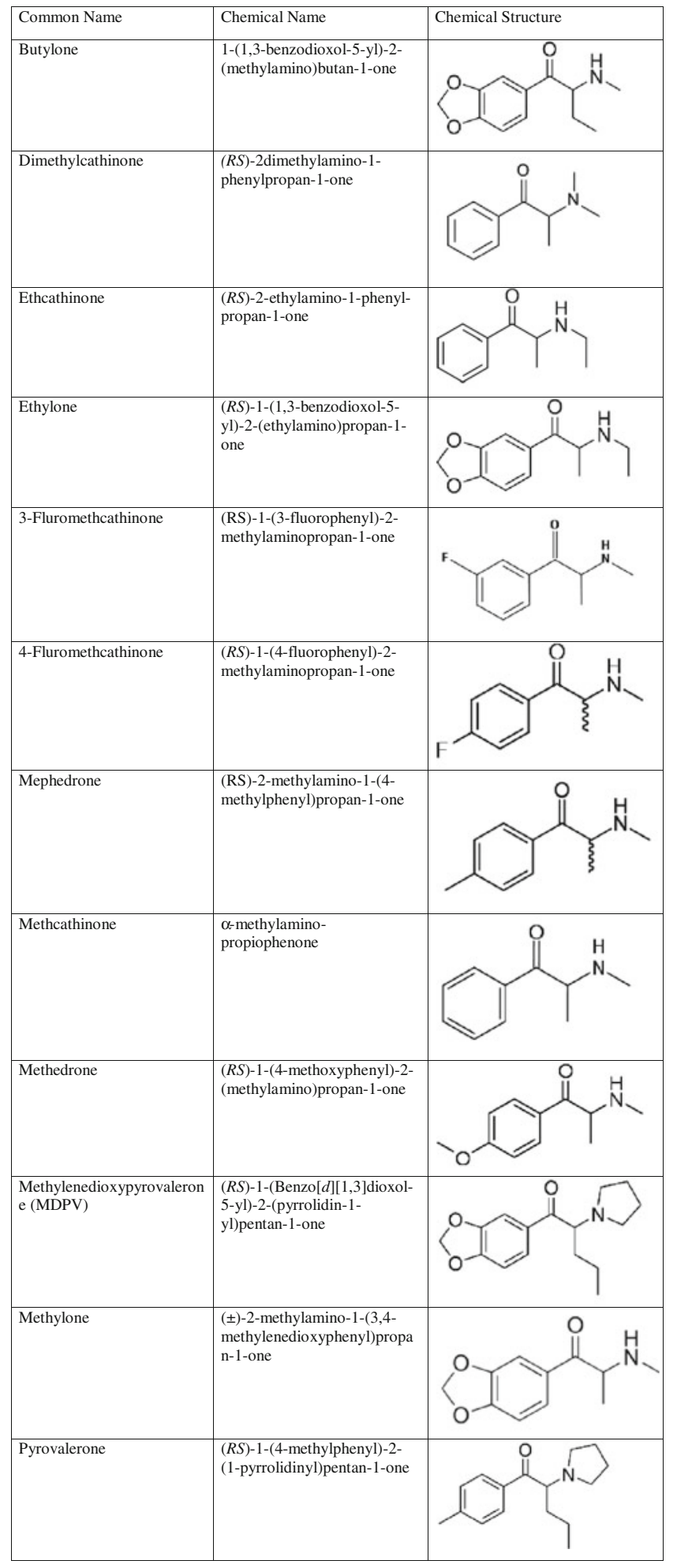

more typical abusable drugs. In 2009, police reports from the UK, showed a marked decrease in purity of cocaine from over $60 \%$ to $22 \%$, which was attributed to an increased number of 
drug seizures [15]. In the Netherlands, a change in the composition of tablets reported to contain MDMA was noted over a similar time period. Prior to 2009, analysis of "Ecstasy" tablets found that $>90 \%$ contained MDMA, although in later samples fewer than half contained any of this substance. In these latter analyses, piperazine derivatives and mephedrone replaced MDMA [16].

\section{Prevalence}

As with many drugs of abuse, the prevalence of synthetic cathinone use is difficult to measure. Self-reported use from user surveys provides most of the currently available prevalence data. An online survey of club-goers in the UK found that $41 \%$ had used methedrone and $10 \%$ had used methylone. A third had used methedrone in the last month and $14 \%$ reported weekly use [17]. High school and college students in the UK asked to self report revealed that $20 \%$ had used mephedrone on at least one occasion, $4 \%$ reported daily use, and all of those using daily were under 21 years of age [18].

A study from Ireland analyzing urine collected from attendees at a methadone maintenance clinic found that $14 \%$ were positive for mephedrone and $3 \%$ were positive for methylone [19].

A Finnish study which analyzed blood from drivers suspected by police to be driving under the influence of drugs found that 286 of 3,000 specimens submitted for analysis contained MDPV (8.6\%). Two hundred eight of these drivers underwent psycho-physical achievement deficiency testing (such as walking in a straight line and speaking without slurred speech) as an indirect measure of driving impairment. Of these, $84 \%$ were functionally impaired, with $7 \%$ of these classified as severely impaired. Many users had multiple substances identified on blood analysis, including benzodiazepines, other amphetamines, tetrahydrocannabinol, and ethanol, so impairment cannot be attributed solely to MDPV in this series [10].

In the United States, data on prevalence and use is extremely limited. The American Association of Poison Control Centers reports 303 calls related to "bath salts" in 2010. As of May 2011, 2,371 calls have already been recorded [20].

\section{Contents}

Contributing to the complexity of understanding the prevalence of use of these drugs is the difficulty in determining the exact nature of the exposure. The true contents of the product can be obscured as advertising and packaging of these products is often misleading. "Bath salts" sold on websites reporting benign active ingredients, such as amino acids, phosphates, and magnesium salts, were found to contain synthetic cathinones [21]. Alternatively, other products advertised as containing synthetic cathinones as the active ingredients actually contained caffeine and local anesthetics [22]. Products advertising "legal highs" have been found to contain scheduled ingredients. In the UK in April 2010, mephedrone and several other cathinone derivates were listed as class B drugs after changes were made to the Misuse of Drugs Act [23] (under UK law, drugs are classified in three categories based on danger of use and corresponding severity of legal consequences. Class A drugs are considered the most dangerous and carry the harshest penalties). Naphyrone, another derivative, remained legal until additional changes were enacted in July 2010. A study conducted in the interim period (April through July) investigated the ingredients of substances advertised online as legal for purchase because they contained the still unclassified naphyrone. Despite the assurances, these products contained controlled synthetic cathinones, placing users at legal as well as medical risk. Consistency of ingredients is also unpredictable. "Legal high" brand name products, analyzed over a 6month period, changed ingredients in $25 \%$ of the samples [24].

Mephedrone users report obtaining the drugs from both Internet sources and local dealers. The number of users who purchased from dealers increased significantly after regulatory measures restricting possession, sale, and manufacture of synthetic cathinones passed in the UK [18, 25]. Synthetic cathinones can be purchased as powder or in pill or capsule form. UK specimens submitted to forensic providers were in powder form $95 \%$ of the time [26]. The cost of $1 \mathrm{~g}$ of mephedrone was approximately $£ 16(\$ 25)$ in the UK, increasing with the change in legal status from approximately $£ 10$ prior to regulation [25]. In the US, $1 \mathrm{~g}$ costs approximately $\$ 20-35$ in head shops or through the Internet [13].

\section{Patterns of Use}

The synthetic cathinones are most commonly nasally insufflated or ingested [1, 27]. "Bombing" is a method of ingestion whereby mephedrone powder is wrapped in cigarette paper and swallowed [28]. "Keying" is the practice of dipping a key into powder and then insufflating. There are approximately five to eight "keys" per gram [6]. Rectal administration, gingival delivery, inhalation, and intramuscular or intravenous injection have also been described [11, 28]. Additionally, multiple concomitant routes of administration are reported [1, 17, 27, 29]. Selfreported doses range from a few milligrams to over $1 \mathrm{~g}$ of 
powder $[6,17,25,27]$. Users cannot be certain of the actual contents or the purity of the drug, therefore actual exposure is highly variable $[22,24]$.

Mephedrone users report the onset of psychoactive effects after insufflation to be 10-20 min with an expected duration of effect of about 1-2 h; onset after oral ingestion is approximately 15-45 min with duration of 2-4 h. Intravenous users report symptoms peaking at 10-15 min with a 30 min duration of desired effects $[26,28]$.

\section{Subjective User Effects}

Desired effects reported by users of synthetic cathinones include increased energy, empathy, openness, and increased libido $[17,30]$.

Approximately $20 \%$ of users surveyed report having had an adverse effect from use of mephedrone [18, 27]. Users report increased sweating, palpitations, nausea and vomiting, headache, muscle twitching, dizziness, vertigo, or short-term memory difficulty (see Table 2).

When asked to compare mephedrone use to cocaine 60 $75 \%$ reported a longer duration of effect and $50 \%$ reported a "better" effect with the former. More than $50 \%$ believed it was less addictive than cocaine. Half thought mephedrone use was equally as risky as cocaine use, with $25 \%$ feeling it was less safe and another $25 \%$ safer $[17,28]$.

Polysubstance abuse, both simultaneous use and on different occasions, is very common among those taking synthetic cathinones. Alcohol, tobacco, MDMA, cannabis, and cocaine were also reported by $>80 \%$ of respondents surveyed about mephedrone use, in addition to an extensive list of other drugs of abuse [17]. All emergency department patients in one series presenting after reported methedrone use had also used other drugs [31]. Urine drug screening in another series found that 16 of 17 specimens were positive for other drugs of abuse [13]. Postmortem toxicology testing has also revealed that concurrent use of other substances is common [32-34]

\section{Adverse Clinical Effects of Synthetic Cathinones}

Cardiac, psychiatric, and neurological signs and symptoms are the most common adverse effects reported in synthetic cathinone users who require medical care. There are four series detailing clinical effects of cathinones. In all, the single most common symptom was agitation ranging from mild agitation to severe psychosis requiring chemical restraint. Retrospective data from the UK Poisons information service, detailing telephone caller and internet reports of presumed cathinone exposures, noted that $28 \%$ of cases had agitation and aggression [1]. A clinical series of 72 patients who presented to a London emergency department found that $39 \%$ were agitated. Nine of the patients in this series had laboratory confirmation of mephedrone ingestion [30]. In a retrospective review of self-reported exposures in a Scottish emergency department agitation was the most common symptom [35]. Similarly, in a prospective US series $66 \%$ were agitated [13]. Cardiovascular complications were also very common, and as a group were the most common complications seen in users presenting for medical care. See Table 3 for a comparison of the clinical effects found in these four review articles.

Table 4 provides a more detailed look at specific signs and symptoms reported in the literature by health care providers about patients with reported use of these products.

Table 2 User reported clinical effects of synthetic cathinones [17, 25, 28, 30, 62]

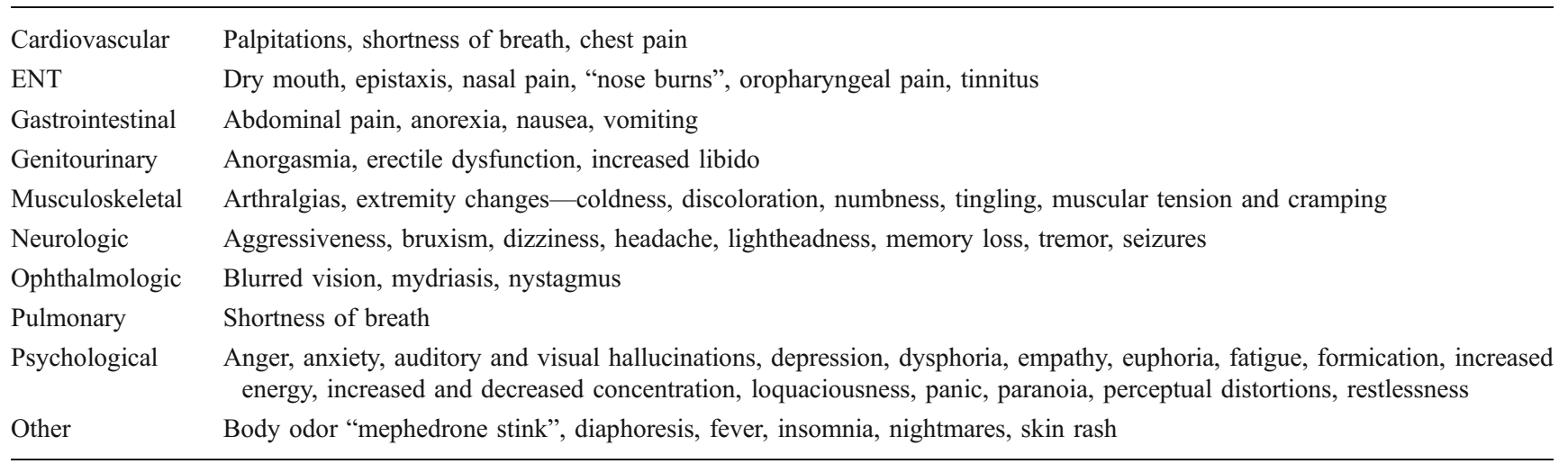

These are self-reported symptoms by users of synthetic cathinones. It is possible that these effects are not all related to cathinone use as many users take these substances simultaneously with other drugs and ethanol. Additionally due to lack of reliability and consistency of products, users may not be aware of what drug they have actually taken. Please see text for more information 
Table 3 Adverse effects reported by healthcare providers from patients seeking medical care after synthetic cathinone use

\begin{tabular}{llllll}
\hline & James [1] & $\begin{array}{l}\text { MMWR } \\
{[13]}\end{array}$ & $\begin{array}{l}\text { Regan } \\
{[35]}\end{array}$ & $\begin{array}{l}\text { EMCDDA } \\
{[30]}\end{array}$ & Total \\
\hline \# patients & 149 & 35 & 57 & 72 & 313 \\
Cardiac & 113 & 30 & 26 & 63 & 293 \\
Psychiatric & 84 & 44 & 37 & 28 & 193 \\
Neurologic & 56 & 18 & 26 & 9 & 109 \\
Gastrointestinal & 27 & NA & 3 & 10 & 40 \\
Pulmonary & 13 & NA & 10 & NA & 23 \\
Ear, nose and throat & 7 & NA & 7 & NA & 14 \\
Other & 48 & NA & 8 & NA & 56 \\
\hline
\end{tabular}

It is possible that these effects are not all related to cathinone use. Only a few of these cases were analytically confirmed as synthetic cathinone exposures. Additionally, many other substances such as ethanol and other drugs of abuse were reported or found on drug screening

Hyponatremia is a well-reported complication of MDMA use. It is thought to result from several factors including overhydration with water in the setting of druginduced secretion of vasopressin [36]. It is unclear if synthetic cathinones cause similar changes in sodium and water regulation. There are three cases of hyponatremia reported after synthetic cathinone exposure, raising the possibility that similarities may exist. In all three cases mephedrone exposure was confirmed and no MDMA was found on body fluid analysis in these patients. A 14-yearold girl who consumed ethanol and a white powder presented with an altered mental status and Glasgow coma score of 11. She had hyponatremia $118 \mathrm{mmol} / \mathrm{L}$ and elevated intracranial pressure, and a brain MRI showing subcortical white matter changes. Her neurologic symptoms improved with correction of the sodium except for mild dysphasia and anterograde amnesia. Two months later, she had complete resolution of all symptoms [37]. The other two cases were both fatalities. A 29-year-old British man presented to the emergency department with a fluctuating level of consciousness, hyponatremia $125 \mathrm{mmol} / \mathrm{L}$, and was found to have cerebral edema with impending tonsillar herniation on head computed tomography. He died after care was withdrawn due to brain death [38]. An 18-year-old woman who used cannabis and mephedrone sustained a cardiac arrest. She was resuscitated, found to have hyponatremia $120 \mathrm{mmol} / \mathrm{L}$ and cerebral edema, but was declared brain dead $36 \mathrm{~h}$ after presentation [39].

\section{Treatment}

Treatment for patients with exposure to synthetic cathinones is primarily supportive. At this time, limited information is available to guide treatment. Benzodiazepines have been used for sedation for agitation and seizures. Given the similarities to amphetamines and cocaine, it seems likely that similar management strategies would be useful. Patients showing signs of the sympathomimetic toxidrome including agitation, psychosis, significant tachycardia, hypertension, and seizures should be treated with benzodiazepines to counteract excessive epinephrine and norepinephrine release and reuptake inhibition. Hyperthermia should be treated with aggressive cooling. Treatment of hyponatremia due to synthetic cathinones is not well described; MDMA-induced hyponatremia is treated with water restriction or hypertonic saline. Management should be directed by the severity of symptoms, and patients may benefit from an approach similar to that of MDMA-induced

Table 4 Medical provider (including emergency department and poison center data) reported effects associated with use of synthetic cathinones $[1,13,30,35,38,70-72]$

\begin{tabular}{ll} 
Cardiovascular & Chest pain, hypertension, palpitations, myocarditis, tachycardia \\
ENT & Epistaxis, oral and pharyngeal effects, tongue disorder \\
Gastrointestinal & Abdominal pain, abnormal liver function tests, nausea, liver failure \\
Musculoskeletal & Elevated creatinine kinase, peripheral vasoconstriction, rhabdomyolysis \\
Neurologic & Agitation, aggression, altered mental status, collapse, confusion, dizziness, drowsiness, dystonia, headache, \\
& hyperreflexia, myoclonus, paraesthesias, seizures, tremor \\
Ophthalmologic & Abnormal vision, mydriasis \\
Pulmonary & Shortness of breath, tachypnea \\
Psychological & Anxiety, confusion, delusions, hallucinations, paranoia, psychosis \\
Renal & Abnormal renal function, acute renal failure \\
Other & Diaphoresis, fever, hyponatremia, rash \\
\hline
\end{tabular}

It is possible that these effects are not all related to cathinone use as many users take these substance simultaneously with other drugs and ethanol. Additionally due to lack of reliability and consistency of products, users may not be aware of what drug they have actually taken. Please see text for more information 
hyponatremia until further understanding specific to cathinones is reached.

\section{Postmortem}

\section{Mephedrone}

A decedent with hyponatremia from Sweden is the first reported death related solely to mephedrone [39]. Since that time, other mephedrone-related deaths have been identified. In many of these cases, investigation and analysis are ongoing to determine the role of mephedrone in causing death.

A report on four mephedrone-associated deaths noted that mephedrone was the principle cause of death in one case. A 19-year-old male used mephedrone, MDMA and alcohol, several hours later began to shake and twitch, and then was found "his eyes were rolling and he was choking". He had cardiorespiratory arrest en route to the hospital and was declared dead on arrival. Postmortem analysis revealed alcohol, 3-trifluoromethylphenylpiperazine, and mephedrone. A second decedent in this series was a 49-year-old woman who developed chest pain and vomiting after insufflating methedrone, drinking alcohol, and smoking cannabis. Her death was attributed to mephedrone, with cardiac fibrosis and atherosclerotic disease as contributing factors. Mephedrone was a contributing factor in two cases: one, a patient with a multidrug overdose and another with a fatal motor vehicle crash [33]. Four additional mephedronerelated deaths are reported: stab wounds were the cause of death in one, mephedrone responsible for two, and the other case unresolved [34]. Accidental death due to multidrug toxicity occurred after use of mephedrone and heroin in a 22-year-old male [32]. Mephedrone was thought to be the cause of death in a person with excited delirium that was aggravated by blood loss from wounds sustained from breaking windows. However, multiple substances were found in the postmortem blood including cocaine, metabolites, and MDMA [40].

\section{Methedrone}

Two methedrone-associated deaths classified as accidental have been reported in Sweden. One patient had marked hyperthermia to $42^{\circ} \mathrm{C}$. Both patients were found to have pulmonary congestion and edema on postmortem examination [41].

\section{Butylone}

Two butylone-associated deaths have been reported. In the first, a man died from injuries due to a fall from height was also found to have butylone in his blood. In another, a woman reported to have died after ingestion of several drugs, was found to have brain edema, pulmonary congestion and hemorrhages, as well as congestion of the liver, spleen and kidneys. She was noted to have subendocardial hemorrhage in the aortic outflow tract as well as contraction band necrosis of the heart [42].

Deaths from use of MDPV and other synthetic cathinones have not been well documented or reported in the medical literature at this time.

\section{Chemistry}

Synthetic cathinones are phenylalkylamines derivatives, and are often termed bk-amphetamines due to a ketone attached at the beta position on the amino alkyl chain attached to the phenyl ring [43]. Similar to phenylethylamines like MDMA, they may possess both amphetaminelike properties and the ability to modulate serotonin, causing distinct psychoactive effects. Most cathinone derivatives have sympathomimetic effects; other qualities, including duration and the extent of psychoactive effects, vary based to a large extent on functional group structure. As a group, they are considered to be less potent than their corresponding phenylethylamine analogue due to increased polarity caused by the beta-ketone, resulting in decreased penetration of the blood brain barrier [26].

There are no published human data on the pharmacokinetics and pharmacodynamics of the currently popular synthetic cathinones. A limited understanding of the mechanism of action and metabolism of these drugs is available mostly from in vitro studies and animal models. Amphetamines and derivatives exert their effects by increasing synaptic concentrations of biogenic amines, such as norepinephrine, dopamine, and serotonin. The increases occur via two primary mechanisms. First, these drugs inhibit monoamine uptake transporters, causing decreased clearance of the neurotransmitters from the synapse. Second, they cause release of the neurotransmitters from intracellular stores. Increased intracellular release occurs via changes in vesicular $\mathrm{pH}$ as well as inhibition of the vesicular monoamine transport (VMAT2) receptor. VMAT2 is located on the vesicular membrane and responsible for monoamine uptake into the vesicles for storage [44].

In comparison to amphetamines and MDMA, understanding of the mechanism of action of synthetic cathinones is limited. However, based on similarities in structure, similar mechanisms are expected. This assumption is supported by user reports which suggest there are both stimulant effects (use is compared to amphetamine use) and psychoactive effects (compared to use of MDMA or LSD) [28]. Furthermore, in an animal model, synthetic cathinones 
were found to be substitutes for rats trained to recognized administration of amphetamine and MDMA [45].

\section{Mechanism: Methylone}

Methylone was found to be equally as potent as methamphetamine and MDMA at inhibiting reuptake of norepinephrine and dopamine in human platelets due to inhibition of monoamine uptake transporters $[44,46]$. There is some controversy in the literature about its potency at serotonin reuptake inhibition compared to other amphetamine derivatives, with several studies finding decreased potency and at least one study finding no difference [44, 46, 47]. Methylone was significantly less potent at VMAT2 receptor inhibition than methamphetamine and MDMA [44]. Interestingly, inhibition of NE reuptake was competitive, while inhibition at serotonin and dopamine receptors was noncompetitive [44]. Additionally, methylone inhibition may cause reverse transport of neurotransmitters from the nerve terminal into the synapse, as is described with methamphetamine [46].

\section{Mechanism: Mephedrone}

Brain concentrations of dopamine in rats given a single dose of $3 \mathrm{mg} / \mathrm{kg}$ of mephedrone peaked in $20 \mathrm{~min}$, and returned to baseline in $100-120 \mathrm{~min}$. When compared to MDMA, it was less potent at increasing serotonin brain concentrations, but caused a greater increase in dopamine. The rate of return of neurotransmitters to the baseline concentration was rapid, ten times faster than the rate of return with MDMA and two times faster when compared to amphetamine [48].

\section{Mechanism: Pyrovalerone}

Pyrovalerone has inhibitory effects on both norepinephrine and dopamine reuptake [49-51] but in a single study, had little effect on serotonin reuptake. Examination of the chirality of the compound revealed the $S$-enantiomer to be the more biologically active than the $R$-enantiomer [52].

Understanding of the metabolism of synthetic cathinones is also limited with most of the information described derived from animal models.

\section{Metabolism: Pyrovalerone}

Pyrovalerone kinetics in mice given both oral and intravenous injections revealed rapid absorption, with only $29 \%$ of the dose remaining in the stomach $30 \mathrm{~min}$ after ingestion. Four hours after ingestion $70 \%$ had been excreted in the urine. After intravenous injection, metabolites were identified in the urine after $5 \mathrm{~min}$ and $20 \%$ had been excreted in $20 \mathrm{~min}$. Ninety percent was eliminated as metabolites in the urine and $6-8 \%$ as the parent compound in the feces. The highest concentrations of the drug were found in the bile, liver, and kidney with the highest concentrations found 30 min after oral administration. A very small fraction, less than $1 \%$, was found in the brain. In the mice and in one human volunteer, no pyrovalerone was found in the urine, the major metabolite found was 4-(1-pyrrolidinylvaleroyl) benzoic acid [53].

Metabolism: Methylone, Ethylone, Butylone

The metabolism of this group of cathinones is best characterized. Some of the parent compounds are excreted unchanged in the urine. Primary metabolism begins with demethylation of the methylenedioxy ring, followed by catechol $O$-methyltransferase (COMT) mediated $O$-methylation into 4'-hydroxy-3'-methoxy $\left(4^{\prime}-\mathrm{OH}-3^{\prime}-\mathrm{MeO}\right)$ or $3^{\prime}$ hydroxy-4'-methoxymethcathinone ( $\left.3^{\prime}-\mathrm{OH}-4^{\prime}-\mathrm{MeO}\right)$. These metabolites are partially conjugated with glucuronides and sulfates and excreted in the urine [54]. N-dealkylation is another possible pathway for metabolism, but appears to play a minimal role. Some bk-amphetamines can be reduced at the ketone group to the corresponding amino alcohols. This appears to be a minor pathway for butylone and ethylone in humans, which is not utilized for methylone [43].

Analysis of the urine of rats after a $5 \mathrm{mg} / \mathrm{kg}$ dose of methylone revealed that $4{ }^{\prime}$-hydroxy-3'-methoxymethcathinone was the most common metabolite, followed by $3^{\prime}$ hydroxy-4'-methoxymethcathinone, methylone, and 3,4methylenedioxycathinone. Both methylone and 4'-hydroxy-3'-methoxymethcathione concentrations peaked $4 \mathrm{~h}$ after parent drug administration. Methylone was undetectable $36 \mathrm{~h}$ after exposure, while 4'-hydroxy-3'-methoxymethcathinone persisted for $48 \mathrm{~h}$ after. Analysis of urine of one human user showed similar metabolites to those found in the rat [55].

\section{Metabolism: Mephedrone}

$\mathrm{N}$-demethylation to a primary amine, followed by reduction of the ketone moieties to alcohols, then oxidation of the totyl group to the corresponding alcohol. Some of the alcohols are conjugated via sulfation or glucuronidation and excreted in the urine [56].

\section{Metabolism: MDPV}

Metabolism in human liver cells appears similar to that of other synthetic cathinones. Examination of MDPV metabolism in human liver cells revealed the following steps. First, opening of the methylenedioxy ring, followed by demethylation leading to a catechol ring which is subsequently 
methylated by COMT. Glucuronidation and sulfation of some metabolites follow. In this one study, $80 \%$ of MDPV was unmetabolized, $10 \%$ was metabolized to methylcatechol pyrovalerone and $7 \%$ to catechol pyrovalerone, though the authors postulated this could have resulted from the very high concentrations of MDPV used [57]. In another study based on examination of rat urine, MDPV underwent a more complicated metabolism, including oxidative and hydroxylation steps. In this same study, MDPV was found to be metabolized in vitro by CYP isoenzymes $2 \mathrm{C} 19,2 \mathrm{D} 6$, and $1 \mathrm{~A} 2$ [58].

Cytotoxic effects of methylone have been found in rat hepatocytes and hamster ovarian cells [46, 59]. Mitochondrial dysfunction due to uncoupling of oxidative phosphorylation was thought to be the source of the cytotoxicity in the hepatocytes [59].

\section{Addiction and Withdrawal}

There is currently no focused research on the addiction potential or withdrawal syndromes related to synthetic cathinones. A survey of 1,500 mephedrone users found that over $50 \%$ consider it to be addictive [27]. In a telephone survey of 100 mephedrone users, nearly half reported continuous use for more than $48 \mathrm{~h}$. Over $30 \%$ reported having more than three of the Diagnostic and Statistic Manual IV criteria for dependence including increased tolerance, continuing to take despite having problems with use and impaired control of use. Fifteen percent reported that friends or family had expressed concern over their mephedrone use [17]. In a Scottish survey of 1,006 students, daily use was reported $4.4 \%$ of users, all of whom were less than 21 years of age. The highest frequency of daily use was in the 11-15-year age group. In the same study, $17.5 \%$ of users reported "addiction/dependence" symptoms [18]. One case report describes a patient who fulfilled criteria for addiction to mephedrone after 18 months of daily use [60].

Users describe strong cravings to repeat or increase doses after taking mephedrone. Users describe this feeling as the drug being very "moreish", meaning that it causes the user to want to ingest more shortly after use [11, 28, 61], and call taking multiple doses in succession "fiending" [62].

A physical withdrawal syndrome has not been reported although users report feelings of depression and anxiety at the end of use. In one study, $25 \%$ of users reported urges or cravings to continue using [17].

\section{Laboratory Analysis}

Synthetic cathinones can be identified using gas chromatography-mass spectrometry or liquid chromatography-mass spectrometry techniques [63-65]. They can be measured in blood, urine, and stomach contents in both pre and postmortem specimens. Correlation of concentrations with clinical effects is not well understood.

Blood concentrations of methedrone in specimens taken from suspected drug offenders ranged in one series from 0.2 to $4.8 \mu \mathrm{g} / \mathrm{g}$ blood [41].

Mephedrone concentrations in urine specimens taken after use in the preceding $24 \mathrm{~h}$ ranged from 0.6 to $7.35 \mathrm{mg} / \mathrm{mL}$ [17]. Concentrations in postmortem blood specimens in mephedrone-related deaths have ranged from 0.13 to $22 \mathrm{mg} / \mathrm{L}[33,34]$. Gastric contents in one case were found to have a concentration of mephedrone of $1.04 \mathrm{mg} / \mathrm{L}$ [40]

Postmortem butylone concentrations in the blood have been reported ranging from 0.435 to $1.2 \mathrm{mg} / \mathrm{L}$ and in gastric contents at $5.2 \mathrm{mg} / \mathrm{L}$ [42].

Synthetic cathinones can be analyzed in hair. A rat model suggests that cathinone and methcathinone are poorly incorporated into hair, but that methylone is well incorporated [66]. Mephedrone has been found in human hair on postmortem examination in concentrations of 4.2 $4.7 \mathrm{ng} / \mathrm{mL}$ [34]. Methedrone has also been found in postmortem concentration of $29-37 \mathrm{ng} / \mathrm{mL}$ [41].

\section{Legal Status}

The legal status of the synthetic cathinones is variable among countries and is changing rapidly. Until recently in the United States, they were unscheduled, but illegal for human consumption under the Federal Analogue Act of 1986. This law was passed in an attempt to prevent use of "designer drugs" which were analogs of other illegal drugs of abuse manufactured with small chemical changes to subvert existing regulatory laws. This law does not criminalize possession or manufacture of the substances, unless intended for human consumption [67]. However, on September 7 2011, the DEA used its emergency scheduling authority to enact temporary control scheduled to begin in approximately 30 days. Possession or sale of mephedrone, MDPV and methylone will be illegal for 1 year while further evaluation is undertaken to consider the need for permanent control [68]. In December of 2010, mephedrone was banned throughout the European Union [69].

\section{Conclusion}

The dramatic rise of the synthetic cathinones as novel drugs of abuse highlights ways in which the Internet is modulating use of drugs by increasing information sharing through drug use websites and increasing availability of drugs by expanding access for purchase. Exposure to and use of 
synthetic cathinones are increasingly popular despite a lack of scientific research and understanding of the potential harms of these substances. The clinical similarities to amphetamines and MDMA specifically are predictable based on the chemical structure of this class of agents. More work is necessary to understand the mechanisms of action, toxicokinetics, toxicodynamics, metabolism, clinical and psychological effects as well as the potential for addiction and withdrawal.

Conflicts of Interest No funding is associated with this project. The authors have no conflicts of interest.

\section{References}

1. James D, Adams RD, Spears R et al (2010) Clinical characteristics of mephedrone toxicity reported to the UK National Poisons Information Service. Emerg Med J. Epub ahead of print

2. Google. Insights for search (2011) http://www.google.com/ insights/search/. Last accessed 7/1/2011

3. Al-Motarreb A, Al-Habori M, Broadley KJ (2010) Khat chewing, cardiovascular disease and other internal medical problems; the current situation and directions for future research. J Ethnopharmacol 132:540-548

4. Hyde JF, Browning E, Adams R (1928) Synthetic homologs of D, L-ephedrine. J Am Chem Soc 50(8):2287-2292

5. Saem de Burnaga Sanchez J (1929) Sur un homologue de la Societé Chimique de France. 45:284-6

6. Advisory Council on the Misuse of Drugs. Consideration of the cathinones. http://www.homeoffice.gov.uk/publications/alcoholdrugs/drugs/acmd1/acmd-cathinodes-report-2010?view=Binary. Last accessed 7/1/2010

7. Emerson TS, Cisek JE (1993) Methcathinone: a Russian designer amphetamine infiltrates the rural Midwest. Ann Emerg Med 22 (12):1897-1903

8. Gardos G, Cole JO (1971) Evaluation of pyrovalerone in chronically fatigued volunteers. Curr Ther Res Clin Exp 13 (10):631-635

9. Goldberg J, Gardos G, Cole JO (1973) A controlled evaluation of pyrovalerone in chronically fatigued volunteers. Int Pharmacopsychiatry 8(1):60-69

10. Kriikku P, Wilhelm L, Schwarz O, Rintatalo J (2011) New designer drug of abuse: 3,4-methylenedioxypyrovalerone (MDPV). Findings from apprehended drivers in Finland. Forensic Sci Int 210(1-3):195-200

11. Psychonaut WebMapping Research Group (2009) Mephedrone. Report. London, UK, Institute of Psychiatry, King's College London

12. Archer RP (2009) Fluoromethcathinone, a new substance of abuse. Forensic Sci Int 185(1-3):10-20

13. Centers for Disease Control and Prevention (2011) Emergency department visits after use of a drug sold as "bath salts"Michigan, November 13, 2010-March 31, 2011. MMWR Morb Mortal Wkly Rep 60(19):624-627

14. The Poison Review. http://www.thepoisonreview.com/2010/11/30/ 2093/. Last accessed 6/10/2001

15. Measham F, Moore K, Newcombe R, Welch Z (2010) Tweaking, bombing, dabbing and stockpiling: the emergence of mephedrone and the perversity of prohibition. Drug Alcohol Today 10(1):14-21
16. Brunt TM, Poortman A, Niesink RJ, van den Brink W (2010) Instability of the ecstasy market and a new kid on the block: mephedrone. J Psychopharmacol. Epub ahead of print

17. Winstock AR, Mitcheson LR, Deluca P et al (2011) Mephedrone, new kid for the chop? Addiction 106(1):154-161

18. Dargan PI, Albert S, Wood DM (2010) Mephedrone use and associated adverse effects in school and college/university students before the UK legislation change. QJM 103(11):875-879

19. McNamara S, Stokes S, Coleman N (2010) Head shop compound abuse amongst attendees of the Drug Treatment Centre Board. Int Med J 103(5):134-137

20. American Association of Poison Control Centers. www.aapcc. org./dnn/default.aspx. Last accessed 7/10/2010

21. Ramsey J, Dargan PI, Smyllie M et al (2010) Buying 'legal' recreational drugs does not mean that you are not breaking the law. QJM 103(10):777-783

22. Brandt SD, Sumnall HR, Measham F, Cole J (2010) Second generation mephedrone. The confusing case of NRG-1. BMJ 341: c3564

23. The Misuse of Drugs (Amendment) (England, Wales and Scotland) Regulations 2010. http://www.legislation.gov.uk/uksi/2010/1144/ made. Last accessed 7/22/2010

24. Davies S, Wood DM, Smith G et al (2010) Purchasing 'legal highs' on the Internet - is there consistency in what you get? QJM 103(7):489-493

25. Winstock AR, Mitcheson LR, Marsden J (2010) Mephedrone: still available and twice the price. Lancet 376(9752):1537

26. EMCDDA-Europol joint report on mephedrone. http://www. emcdda.europa.eu/online/annual-report/2010/boxes/p92. Last accessed 7/12/2010

27. Carhart-Harris RL, King LA, Nutt DJ (2011) A web-based survey on mephedrone. Drug Alcohol Depend. Epub ahead of print

28. Newcombe R (2009) Mephedrone: use of mephedrone (M-Cat, Meow) in Middlesbrough. Lifeline, Manchester, UK

29. Wood DM, Davies S, Puchnarewicz M et al (2010) Recreational use of mephedrone (4-methylmethcathinone, 4-MMC) with associated sympathomimetic toxicity. J Med Toxicol 6(3):327-330

30. Dargan P, Wood D (2010) Technical report on mephedrone, 2010. European Monitoring Centre for Drugs and Drug Addiction. Risk assessment report of a new psychoactive substance: 4methylmethcathinone (mephedrone). EMCDDA, Lisbon

31. Wood DM, Greene SL, Dargan PI (2011) Clinical pattern of toxicity associated with the novel synthetic cathinone mephedrone. Emerg Med J 28(4):280-282

32. Dickson AJ, Vorce SP, Levine B, Past MR (2010) Multiple-drug toxicity caused by the coadministration of 4-methylmethcathinone (mephedrone) and heroin. J Anal Toxicol 34(3):162-168

33. Maskell PD, De Paoli G, Seneviratne C, Pounder DJ (2011) Mephedrone (4-methylmethcathinone)-related deaths. J Anal Toxicol 35(3):188-191

34. Torrance H, Cooper G (2010) The detection of mephedrone (4methylmethcathinone) in 4 fatalities in Scotland. Forensic Sci Int 202(1-3):e62-e63

35. Regan L, Mitchelson M, Macdonald C (2010) Mephedrone toxicity in a Scottish emergency department. Emerg Med J. Epub ahead of print

36. Henry JA, Fallon JK, Kicman AT, Hutt AJ, Cowan DA, Forsling M (1998) Low-dose MDMA ("ecstasy") induces vasopressin secretion. Lancet 351(9118):1784

37. Sammler EM, Foley PL, Lauder GD et al (2010) A harmless high? Lancet 376(9742):742

38. Wood DM, Davies S, Greene SL et al (2010) Case series of individuals with analytically confirmed acute mephedrone toxicity. Clin Toxicol (Phila) 48(9):924-927

39. Gustavsson D, Escher C (2009) Mephedrone-Internet drug which seems to have come and stay. Fatal cases in Sweden have 
drawn attention to previously unknown substance. Lakartidningen 106(43):2769-2771

40. Lusthof KJ, Oosting R, Maes A et al (2011) A case of extreme agitation after use of mephedrone in the Netherlands. Forensic Sci Int 206(1-3):e9395

41. Wikström M, Thelander G, Nyström I, Kronstrand R (2010) Two fatal intoxications with the new designer drug methedrone (4methoxymethcathinone). J Anal Toxicol 34(9):594-598

42. Carter N, Rutty GN, Milroy CM, Forrest AR (2000) Deaths associated with MBDB misuse. Int J Legal Med 113(3):168-170

43. Zaitsu K, Katagi M, Tatsuno M et al (2011) Recently abused b-keto derivates of 3,4-methylenedioxyphenylalkylamines: a review of their metabolisms and toxciological analysis. Forensic Toxicol 29(2):73-84

44. Cozzi NV, Sievert MK, Shulgin AT et al (1999) Inhibition of plasma membrane monoamine transporters by beta-ketoamphetamines. Eur J Pharmacol 381(1):63-69

45. Dal Cason TA, Young R, Glennon RA (1997) Cathinone: an investigation of several $N$-alkyl and methylenedioxy-substituted analogs. Pharmacol Biochem Behav 58(4):1109-1116

46. Sogawa C, Sogawa N, Ohyama K et al (2011) Methylone and monoamine transporters: correlation with toxicitiy. Curr Neuropharmacol 9:58-62

47. Nagai F, Nonaka R, Satoh Hisashi Kamimura K (2007) The effects of non-medically used psychoactive drugs on monoamine neurotransmission in rat brain. Eur J Pharmacol 559(2-3):132-137

48. Kehr J, Ichinose F, Yoshitake S et al (2011) Mephedrone, compared to MDMA (ecstasy) and amphetamine, rapidly increases both dopamine and serotonin levels in nucleus accumbens of awake rats. Br J Pharmacol. Epub ahead of print

49. Bonnet JJ, Protais P, Chagraoui A, Costentin J (1986) Highaffinity [3H]GBR 12783 binding to a specific site associated with the neuronal dopamine uptake complex in the central nervous system. Eur J Pharmacol 126(3):211-222

50. Servin A, Fauquet JP, Jacquot C, Rapin JR (1978) Effects of pyrovalerone on peripheral noradrenergic mechanisms. Biochem Pharmacol 27(12):1693-1694

51. Vaugeois JM, Bonnet JJ, Costentin J (1992) In vivo labelling of the neuronal dopamine uptake complex in the mouse striatum by [3H]GBR 12783. Eur J Pharmacol 210(1):77-84

52. Meltzer PC, Butler D, Deschamps JR, Madras BK (2006) 1-(4Methylphenyl)-2-pyrrolidin-1-yl-pentan-1-one (Pyrovalerone) analogues: a promising class of monoamine uptake inhibitors. J Med Chem 49(4):1420-1432

53. Michaelis W, Russel JH, Schindler O (1970) The metabolism of pyrovalerone hydrochloride. J Med Chem 13(3):497-503

54. Zaitsu K, Katagi M, Kamata HT et al (2009) Determination of the metabolites of the new designer drugs bk-MBDB and bk-MDEA in human urine. Forensic Sci Int 188(1-3):131-139

55. Kamata HT, Shima N, Zaitsu K et al (2006) Metabolism of the recently encountered designer drug, methylone, in humans and rats. Xenobiotica 36(8):709-723

56. Meyer MR, Wilhelm J, Peters FT, Maurer HH (2010) Beta-keto amphetamines: studies on the metabolism of the designer drug mephedrone and toxicological detection of mephedrone, butylone, and methylone in urine using gas chromatography-mass spectrometry. Anal Bioanal Chem 397(3):1225-1233
57. Strano-Rossi S, Cadwallader AB, de la Torre X, Botrè F (2010) Toxicological determination and in vitro metabolism of the designer drug methylenedioxypyrovalerone (MDPV) by gas chromatography/mass spectrometry and liquid chromatography/ quadrupole time-of-flight mass spectrometry. Rapid Commun Mass Spectrom 24(18):2706-2714

58. Meyer MR, Du P, Schuster F, Maurer HH (2010) Studies on the metabolism of the $\alpha$-pyrrolidinophenone designer drug methylenedioxy-pyrovalerone (MDPV) in rat and human urine and human liver microsomes using GC-MS and LC-highresolution MS and its detectability in urine by GC-MS. J Mass Spectrom 45(12):1426-1442

59. Nakagawa Y, Suzuki T, Tayama S, Ishii H, Ogata A (2009) Cytotoxic effects of 3,4-methylenedioxy- $N$-alkylamphetamines, MDMA and its analogues, on isolated rat hepatocytes. Arch Toxicol 83(1):69-80

60. Bajaj N, Mullen D, Wylie S (2010) Dependence and psychosis with 4-methylmethcathinone (mephedrone) use. BMJ Case Reports. Epub ahead of print

61. Erowid. http://www.erowid.org/chemicals/4_methylmethcathinone/ 4 methylmethcathinone effects.shtml Last accessed 7/12/2010

62. Schifano F, Albanese A, Fergus S et al (2011) Mephedrone (4methylmethcathinone; 'meow meow'): chemical, pharmacological and clinical issues. Psychopharmacology 214(3):593-602

63. Frison G, Gregio M, Zamengo L et al (2011) Gas chromatography/mass spectrometry determination of mephedrone in drug seizures after derivatization with 2,2,2-trichloroethyl chloroformate. Rapid Commun Mass Spectrom 25(2):387-390

64. Maheux CR, Copeland CR (2010) Characterization of three methcathinone analogs: 4-methylmethcathinone, methylone, and bk-MBDB. DEA Microgram J 7(2):42-49

65. Wissenbach DK, Meyer MR, Remane D, Philipp AA, Weber AA, Maurer HH (2011) Drugs of abuse screening in urine as part of a metabolite-based LC-MS(n) screening concept. Anal Bioanal Chem 400(10):3481-3489

66. Kikura-Hanajiri R, Kawamura M, Saisho K, Kodama Y, Goda Y (2007) The disposition into hair of new designer drugs; methylone, MBDB and methcathinone. J Chromatogr B Analyt Technol Biomed Life Sci 855(2):121-126

67. Federal Analogue Act. Controlled Substance Analogue Enforcement Act of 1986, Pub. L. No. 99-570, § 1203, 100 Stat. 3207, 3213-14

68. DEA moves to emergency control synthetic stimulants. http:// www.justice.gov/dea/pubs/pressrel/pr090711.html. Last accessed 09/07/2011

69. Europa. Commission achieves EU-wide ban on ecstasy-like drug mephedrone http://europa.eu/rapid/pressReleasesAction. do? reference $=\mathrm{MEMO} / 10 / 646$. Last accessed 6/14/2010

70. Frolich S, Lambe E, O’Dea J (2011) Acute liver failure following recreational use of psychotropic "head shop" compounds. Ir J Med Sci 180(1):263-264

71. Nicholson PJ, Quinn MJ, Dodd JD (2010) Headshop heartache: acute mephedrone 'meow' myocarditis. Heart 96(24):2051-2052

72. Shimizu E, Watanabe H, Kojima T et al (2007) Combined intoxication with methylone and 5-MeO-MIPT. Prog Neuropsychopharmacol Biol Psychiatry 31(1):288-291 